$$
\text { DOSSIÊ }
$$





\section{DOSSIÊ BÍOS}

$\mathrm{O}$ presente dossiê possui duas finalidades: reunir ensaios sobre aspectos importantes do fenômeno biográfico na Antiguidade e apresentar ao público de língua portuguesa traduçôes de relatos de caráter biográfico que, a princípio, não tenham sido vertidos para o português. Em ambos os aspectos, optou-se por não se restringir ao gênero biográfico stricto sensu e incluir outros tipos de narrativas importantes para a formação do gênero ou para se pensar a constituição de temas ou tópoi biográficos em longa duração. Em certo sentido, o "Dossiê Bíos" reconhece no historiador Arnaldo Momigliano o interlocutor com que se dialoga e a partir de que se faz a mimesis, no duplo sentido grego de emulação e imitação. Dessa forma, a escolha de temas, obras e autores evoca as questôes por ele colocadas em sua obra Les origines de la biographie em Grèce ancienne.

Tendo o gênero biográfico antigo como base para minha pesquisa nos últimos anos, venho me dedicando ao estudo sistemático de vários aspectos e de várias espécies de bios na Antiguidade. Por se estender numa longa extensão de tempo, ele ficou submetido às mais variadas influências de outros campos discursivos e, sem dúvida, dos diversos contextos históricos e culturais. Dessa forma, traçar dele um quadro uniforme ou homogêneo seria uma empresa que não daria conta de suas variantes e subgêneros, assim como do fenômeno biográfico de caráter mais generalizante que atravessa boa parte da produção discursiva ao longo da Antiguidade.

Uma das hipóteses fenomenais de Momigliano relativas à constituição do gênero biográfico aponta para a influência persa tanto na cultura grega quanto na judaica. A partir dessa perspectiva, ele faz uma aproximação entre figuras de pretensos biógrafos gregos no século $\mathrm{V}$ a.C., como Cílax de Carianda e Íon de Quios, e as figuras de Esdras e Neemias na Judéia,, cujos escritos também apresentariam traços auto-biográficos e algum tipo de estruturação biográfica. Por mais que não se advogue uma influência direta 

1. Cf. MOMIGLIANO, Arnaldo. La Naissance de la Biographie en Grèce Ancienne. Traduit de l'Anglais par Estelle Oudot, Strausbourg: Circé, 1991, p. 55-60; JOUANNO, Corinne. Vie d'Ésope, traduite et commentée par Corinne

Jouanno, La Roue à Livres, Paris, 2006, p. 22-27; BOROBIO, E. Martínez. Libro Arameo de Ajicar. IN: MACHO,

Alejandro Diez et alii. Apocrifos del Antiguo Testamento. Tomo III. Madrid: Ediciones Cristiandad, 1982. de modelos persas ou mesmo assírios para a origem da biografia na Grécia, é certo que tais relatos são importantes como testemunhos de textos mais antigos com traços biográficos ou auto-biográficos. Ele se refere, nesse sentido, também às inscrições "autobiográficas" persas, assírias e algumas egípcias.

A história de Ahikar, conhecida como Romance de Ahicar, é uma narrativa emblemática para se auferir esse tipo de influência. A época aí evocada remonta aos reinos de Senaqueribe e Assarhaddon, para os quais Ahicar (figura histórica ou lendária, representativa da classe dos escribas) serviria de conselheiro. Segundo a intriga narrada, depois de adotar o sobrinho Nadan e de instruí-lo, ele é acusado pelo próprio Nadan de tramar contra o soberano Assarhaddon. Embora condenado à morte, Ahicar consegue se salvar e, tempos depois, numa disputa de enigmas entre Assarhaddon e o soberano egípcio, ele volta às graças daquele ao solucionar todos os enigmas propostos. Saindo vitorioso, ele, ao conseguir permissão para castigar o sobrinho, dirige vários reproches em forma de preceitos a Nadan, o qual acaba por se matar. A versão mais antiga dessa narrativa está em aramaico, sendo do século $\mathrm{V}$ a.C. Como é evidente, uma boa parte do enredo, com modificaçōes e alteraçōes, é inserida no relato escriturístico de Tobit e Tobias. Por seu turno, a figura de Ahicar será conhecida por gregos e romanos. Na Grécia, a partir do testemunho de Clemente de Alexandria (Estromata, 1, 15), sabe-se da existência de uma estela de Ahicar, a qual Demócrito teria traduzido no século V a.C. Pelo testemunho de Diógenes Laércio $(5,50)$, verifica-se o interesse de Teofrasto sobre o sábio assírio; além disso, é possível que um mosaico da época romana em Trieste (século III d.C.) possa representar o próprio Ahikar. ${ }^{1}$ A partir da tradução grega desse Romance de Ahikar, é construída uma parte da Vida de Esopo, uma obra do século II d.C., cujo enredo é assimilado e adequado para o percurso biográfico e romanesco de Esopo. Em nosso dossiê, consta a tradução da primeira parte das recensões G e W da Vida de Esopo, mas, por uma questão de extensão, esse entrecho específico (referente a Ahikar) não aparece na tradução.

De uma e de outra forma, consideramos relevante incluir neste dossiê um trabalho sobre inscrições reais 
mesopotâmicas, em que aspectos biográficos, autobiográficos e concernentes à memória são apresentados em sua relação com os feitos de soberanos assírios. Kátia Pozzer, com erudição, charme e virtuose, comenta, interpreta e traduz do acádico para o português alguns excertos do rei assírio Assurbanipal, datados de 668 a 627 a.C. Além de indicar a finalidade propriamente política desses textos, testemunhos de uma "celebração violenta da memória estatal", sua tradução e explicação nos leva a refletir sobre questôes como indicação da origem (no sentido tanto de lugar de procedência quanto de progenitores e ancestrais), relação intrínseca com as divindades, descrições de qualidades e aptidões, itens que se afiguram com tópoi biográficos no gênero posterior do bios; além disso, no segundo excerto traduzido, há uma sequência de ações heróicas realizadas por Assurbanipal, o que, de certa forma, aponta para uma estruturação e narrativa de práxeis, parte essa característica e costumeira no relato de vidas de generais, soberanos e figuras políticas em geral.

$\mathrm{O}$ segundo artigo tem uma finalidade de propiciar uma introdução geral ao tema na Antiguidade, considerando a formação do gênero e retomando variadas categorizações feitas por especialistas na área. Neste trabalho, assinado por mim, redimensiono o conceito de tópos biográfico propondo uma concepção mais abrangente e uma classificação mais apurada em vista de uma análise estreitamente vinculada à forma em que aparecem nos textos. Utilizo-me dessa categorização em vários tópoi biográficos para lidar com um corpus de fragmentos do século $\mathrm{V}$ a.C. (e um provavelmente de fins do século VI a.C.), dos quais forneço uma tradução meramente literal para fins de análise. Embora não haja subsídios para afirmar que fariam parte de narrativas biográficas, como aponta Momigliano, eles são importantes para a constituição do bios, assim como para a própria história da recepção e comentários de tais fragmentos dentro daquilo que concebi como "ambiência biográfica". Neste meu artigo, há apenas alguns apontamentos sobre narrativas biográficas ou com dados auto-biográficos no século IV a. C, como o Evágoras de Isócrates, o Agesilau e a Ciropedia de Xenofonte. No entanto, foi deixado para uma outra publicação um exame mais detido de tais textos, assim como 
dos fragmentos de Aristóxeno, cuja obra também é essencial para se entender a constituição do gênero. Não obstante, podemos contar neste dossiê com a valiosa contribuição de três estudiosas que traduziram e comentaram o que existe de mais relevante (em função da extensão dos fragmentos conservados) de exemplares da biografia do período helenístico.

Gabriela Gazzinelli traduz para o português o mais antigo exemplar de uma biografia helenística, o que revela sua maior relevância pelo fato de toda a produção do período ter restado apenas de forma bastante fragmentária. Embora o texto não esteja em sua íntegra, a dimensão dos fragmentos permite uma avaliação mais apurada e propicia maiores detalhes para a análise. Uma das características mais impressionantes do texto é sua forma dialogada, inteiramente inusual para uma biografia. Essa Vida de Eurípides, escrita por Sátiro, no século III a.C., apresenta duas personagens: um primeiro interlocutor (que poderia se nomear como o próprio Sátiro) e Diodora Eucleia, uma mulher erudita. Como visto, há uma influência do diálogo filosófico platônico em sua composição; Gazzinelli, não obstante, se volta para traços advindos da escola peripatética, como, por exemplo, o tratamento das emoçōes. Esta biografia denuncia também aquilo que se costumou chamar de método Camaleonte, a partir do nome do biógrafo peripatético Camaleonte, o qual tinha a tendência a deduzir dados da vida do biografado a partir das próprias obras. De forma semelhante, Sátiro retirava das tragédias compostas por Eurípides, bem como a partir do que apresenta Aristófanes em suas comédias, qualidades e informações acerca da vida do escritor: sua misoginia, seu caráter misantropo, a profissão da mãe como verdureira etc. Além disso, há várias citações de suas obras com alguns apontamentos de crítica literária.

Mary Lafer e Sandra Rocha comentam e traduzem um autor igualmente importantíssimo para o gênero bíos na Antiguidade, mas também para a história do período romano-helenístico: Nicolau de Damasco. Mary Lafer traduz parte dos fragmentos de sua obra atualmente conhecida como Autobiografia; no caso, o título dado pela

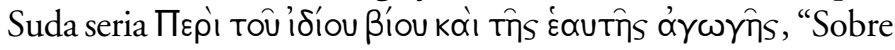
a propria vida e sobre a formação de si mesmo". Ou seja, 
uma biografia sobre si mesmo, como apontava Momigliano, não deixava de ser um bios em termos gerais. Sua Vida de Augusto, cuja primeira parte é traduzida e comentada por Sandra Rocha, antecipa as obras de Suetônio e de Plutarco e, desse modo, é uma fonte primordial para o gênero biográfico, como também para a representação da figura de Augusto em sua época.

O gênero bios vai ser utilizado também por autores judeus que escreveram em língua grega, como é o caso de Fílon de Alexandria com sua Vida de Moisés e de Flávio Josefo com sua Autobiografia, obras essas que assimilam novas características advindas da cultura judaica e da literatura escriturística. A figura de Moisés era emblemática por apresentar a vida de um patriarca dentro de uma concepção de modo de vida propriamente biográfico, tendente à exemplaridade e ao caráter de paradigma. Sinal disso são textos de historiadores que versaram sobre tal patriarca, como Eupólemo e Artápano, cujos fragmentos se depreendem das referências feitas por Alexandre Polístor, cuja obra, por sua vez, nos é conhecida também de forma fragmentária a partir dos testemunhos de Diógenes Laércio e Estéfano de Bizâncio, por um lado, e de Clemente de Alexandria e Eusébio de Cesareia, por outro. Embora não sejam propriamente biográficos, esses fragmentos nos fornecem subsídios para o tratamento do tema no âmbito judaico no período helenístico. Dessa forma, nosso dossiê tem a contribuição inestimável de Cesar Motta Rios que traduz e comenta os fragmentos atribuídos a Artápano, uma figura ainda enigmática, que nem mesmo se confirmaria seguramente como judeu segundo os especialistas, embora tenha escrito sobre temas judaicos, no caso dos fragmentos, sobre Abraão, José e Moisés. Nesses escritos de Artápano se evidencia uma tendência ao sincretismo com incorporação de elementos gregos, judeus e egípcios, tratados de uma forma não muito ortodoxamente judaica. Segundo Concepción López Rodriguez, ${ }^{2}$ o Moisés de Artápano se mostraria muito mais complexo que aquele de Eupólemo: seria, ao mesmo tempo, o personagem bíblico que conduz o seu povo, o integrador de culturas (assumindo, por exemplo, o papel correspondente ao dos sacerdotes egípcios)
2. RODRIGUEZ,

Concepción López. El "Moisés" de Eupólemo y Artápano. In: MARÍN, J.A. Sánchez e alii. Historiografia y biografia. Madrid: Ediciones Clásicas, 1997. 
e também um equivalente de Hermes no que diz respeito ao domínio e ao ensino da linguagem.

Sem dúvida, Plutarco é um dos autores mais conhecidos, no que diz respeito ao gênero biográfico, por sua obra Vidas Paralelas, em que justapõe um grego e um romano, buscando uma comparação entre ambos. Neste dossiê, Maria Aparecida de Oliveira Silva aborda a obra deste escritor segundo uma perspectiva peculiar: o enquadramento de vários tipos de mulheres que aparecem nesses bioi de militares, legisladores e comandantes. Embora não haja escrito um bios especificamente sobre uma mulher, encontram-se em sua obra relatos e descriçōes de várias personagens femininas, as quais são enquadradas por Maria Aparecida segundo as seguintes rubricas: as corajosas, as mães, as dominadoras, as ardilosas, as cortesãs, as infiéis, as convenientes, as casuais, as apaixonadas. A autora nos apresenta uma galeria de tipos distintos de mulheres, que recebem tratamento diferenciado na obra plutarqueana; elas influenciam o jogo político, sendo, por exemplo, o casamento uma estratégia para a projeção social, o que corrobora o poder e a presença feminina, considerados, por sua vez, não meramente marginais na narrativa biográfica de Plutarco.

Aparece em São Jerônimo, numa possível referência a Suetônio, em seu prefácio ao Viris Ilustribus, um cânon de biógrafos, a partir de que quatro escritores gregos de biografias de homens ilustres (Hermipo, Antígono de Caristo, Sátiro e Aristóxeno) corresponderia a quatro escritores latinos: Varrão, Santra, Nepos e Higino. Segundo Giorgio Brugnoli ("Nascita e sviluppo dela biografia romana” In: GALLO, Italo, NICASTRI, Luciano. Biografia e autobiografia degli antichi e dei moderno. Napoli: Edizioni Scientifiche Italiane, 1995, p. 79-107), quer se deva à influência preponderante de modelos helenísticos ou apresente sua originalidade propriamente romana a partir de laudationes funebres, neniae e carmina convivalia, o fenômeno biográfico apareceria em Roma a partir do século II a. C.; para além dos quatro nomes citados no cânon latino suetoniano, encontrar-se-iam os seguintes nomes: Ópio, Cícero, Tíron, Fadio Gallo, Balbo, Munácio Rufo, além de Ático. De uma forma ou de outra, a obra de Suetônio consegue integrar em si vários aspectos da tradição biográfica 
helenística e romana anterior. De sua obra De Grammaticis et Rhetoribus, temos dois artigos: o de Marcos Martinho trata especificamente da primeira parte (com comentário seguido de uma tradução), Dos gramáticos, enquanto Artur Costrino se encarrega da segunda parte, Dos retores. Marcos Martinho chama a atenção para o caráter fisicista ou naturalista que Suetônio fornece à composição da primeira seção, que se afigura como uma história da gramática em Roma, dividida, com efeito, em quatro períodos: tempo do início ou descoberta, tempo do desenvolvimento, tempo da perfeição ou do florescimento, tempo do declínio. A seguir, ele faz uma análise filológica e criteriosa dos termos utilizados em relação aos gramáticos, concernentes às funções, atividades e ensino no papel de mestres e professores, assim como ao seu lugar de ensino, aos discípulos e aos honorários. Por seu turno, Artur Costrino antepóe à sua tradução uma discussão relevante entre as relações entre os gêneros da biografia e da história na Antiguidade, fazendo referência justamente a passagens e autores que Momigliano havia sinalizado como precípuos para distinguir os dois gêneros. Não obstante, cabe sempre lembrar o caráter multifacetado do bios antigo, assim como de concepções diferenciadas da história na Antiguidade; conforme Bruno Gentili e Giovanni Cerri (History and Biography in Ancient Thought. Amsterdam: J. C. Gieben, Publisher: 1988, p. 62-65), há pelo menos duas concepçóes de história: por um lado, uma entendida como referente a séries de eventos políticos e, por outro lado, outra vista como uma espécie de antropologia que abarca todos os aspectos da existência, ou seja, uma história de tipo tucidideano ou polibiano seria bem diferente de outra do modelo de Dionísio de Halicarnasso. Daí que as interrelações entre biografia e história estariam dependentes de uma avaliação acurada entre as diferentes espécies de biografias face a estas duas concepçôes de história, o que demandaria, claro, uma investigação bem mais longa e aprofundada, a qual está fora dos objetivos e do escopo desse primeiro dossiê.

Dentro da diversidade do bios antigo, afigura-se um corpus de obras que, a despeito de possuírem traços marcadamente biográficos (como a indicação do termo bios no título), apresenta uma hibridização acentuada com a 
narrativa romanesca da época. Em vista desse estatuto indecidível entre biografia e romance, são classificadas ora como vidas romanescas ou romanceadas ora como romances biográficos ou biografizantes, consoante a tendência dos pesquisadores. Desse corpus, figuram comentadas e traduzidas neste dossiê a Vida Herodoteana de Homero e a Vida/Romance de Esopo, nas recensões G e W.

Christian Werner e Luiz Guilherme Couto Pereira vertem para o português o primeiro desses textos, com um comentário introdutório: fazem uma discussão acerca do modo de criação de tradições biográficas sobre a figura de Homero, constituídas a partir de um material que em si revelaria o modo de recepção da épica na Antiguidade. Segundo Marie-Andrée Colbeaux (Raconter la Vie d'Homère dans L'Antiquité: Édition commentée du traité anonyme, Au sujet d'Homère et d'Hésiode, de leurs origines et de leur joute, e de la Vie d'Homère attribuée à Hérodote. Tese de doutorado. Université Charles de Gaulle - Lille III, 2004), várias vidas de Homero, como a Vida Herodoteana de Homero, o Certame entre Homero e Hesiodo, as duas Vidas atribuídas a Plutarco, responderiam a um projeto literário por parte de seus autores. Como biografias literárias de poetas, entrariam em pauta questóes de poética, com a utilização de categorias como o elogio e a censura, além de serem influenciadas por reflexões aristotélicas em torno das noçōes de physis e paideia. Testemunhariam, assim, o processo de recepção da poesia homérica, aí incluídos comentários estilísticos, categorizações, crítica e teorização literária.

No último artigo, assinado por mim e Adriane Duarte, são traduzidas partes das duas recensões principais da Vida/Romance de Esopo, G e W, também antecedidas de um comentário introdutório. Em função da extensão da obra, a tradução limitou-se à primeira seção da primeira parte. Assim como a Vida/Romance de Alexandre, a Vida de Esopo passou por um processo de assimilação e compilação de materiais variados, o que, sem embargo, não chegam a obscurecer a unidade e o trabalho de composição do autor. No entanto, a transmissão manuscrita de tais textos vem a ser bem mais complicada, por serem mais suscetíveis que os textos canônicos a receberem acréscimos, alterações e interferências de todo tipo. 
Assim como na Vida Herodoteana de Homero são inseridos epigramas atribuídos ao poeta, assim também na Vida de Esopo estão incluídas fábulas pretensamente compostas pelo biografado. Aí estão igualmente presentes os temas romanescos ligados a viagens e aventuras, pelo que tanto Homero quanto Esopo perfazem o papel do herói. A narrativa concernente a esse último apresenta, por exemplo, muitas similaridades e paralelos com o romance de Apuleio, As Metamorfoses ou Asno de Ouro: ambos, Lúcio e Esopo, passam por uma espécie de ritual na dinâmica narrativa, a partir de que o primeiro, transformado em burro, retoma a forma humana, enquanto o segundo adquire a capacidade de falar, de compor discursos e composições escritas; em ambos os caso, há a ação da deusa Ísis que, responsável pelas transformações, intervém como legitimadora de uma prosa literária e, no caso, romanesca.

Gostaria, por fim, de agradecer a todos os estudiosos que participaram deste dossiê, os quais, com extrema boa vontade, aceitaram a dupla tarefa de traduzir e analisar textos da Antiguidade a partir de abordagens diversas, mas que visavam, de uma forma ou de outra, o gênero do Bíos antigo. Não há aqui um objetivo de tratamento exaustivo de temas e narrativas biográficas, senão um empreendimento inicial para uma reflexão sobre o gênero biográfico antigo, a partir do cotejo com os textos selecionados e traduzidos. As traduçôes aqui apresentadas poderão ser publicadas posteriormente pelos respectivos autores em edições mais completas, com comentários mais pormenorizados e substanciosos.

Pedro Ipiranga Júnior Curitiba, 30 de abril de 2014 